\title{
PUBLICIDAD E INFORMACIÓN SOBRE ELECCIONES EN LOS MEDIOS DE COMUNICACIÓN DURANTE LA CAMPAÑA ELECTORAL
}

\author{
MARÍA HOLGADO GONZÁLEZ \\ Profesora Titular de Derecho Constitucional \\ Universidad Pablo de Olavide
}

SUMARIO

I. La oportunidad de replantear algunos aspectos de la LOREG tras la experiencia de dos elecciones generales seguidas. II. La regulación de los medios de comunicación como soporte para la publicidad y emisores de información durante la campaña electoral. III. Medidas que inciden en la publicidad electoral. IV. El tratamiento de la información política en campaña electoral. V. Reflexiones finales.

\section{LA OPORTUNIDAD DE REPLANTEAR ALGUNOS ASPECTOS DE LA LOREG TRAS LA EXPERIENCIA DE DOS ELECCIONES GENERALES SEGUIDAS}

Por primera vez desde la entrada en vigor de la Constitución española de 1978, el pueblo es convocado, en aplicación de su artículo 99, a elegir unas nuevas Cortes Generales ante la imposibilidad mostrada por las recién constituidas, tras las elecciones de diciembre de 2015, de investir a un gobierno. La convocatoria de unas nuevas elecciones generales en tan breve espacio de tiempo daría lugar a que desde las propias candidaturas se planteasen fórmulas diversas en orden a racionalizar la campaña y reducir el gasto electoral, en un contexto de crisis económica y de cierto hartazgo, cuando no de desafección política por parte de la ciudadanía ${ }^{1}$. Si bien estas propuestas no llegaron a materializarse finalmente para las elecciones de junio

1 Vid. Reviriego Picón, F., «Reformas electorales en un contexto de crisis», Tudela Aranda, J. y Kölling, M. (coords.), Costes y beneficios de la descentralización política en un contexto de crisis: el caso español, Fundación Manuel Giménez Abad, 2015, pp. 205-251. 
de 2016, por falta de acuerdo entre las formaciones políticas², al menos sí sirvieron para que se debatiera políticamente la necesidad de replantear algunos aspectos de la regulación de las campañas electorales por parte de la LOREG y su adecuación a una realidad que ciertamente ha cambiado sin que las distintas reformas aprobadas hasta el momento hayan dado una solución óptima a las nuevas circunstancias.

En efecto, las pasadas elecciones de diciembre de 2015 mostraron un escenario político distinto al que hasta ahora estábamos acostumbrados, con la irrupción de nuevas formaciones políticas con serias expectativas de voto que han alterado el sistema de partidos ampliando las dimensiones del pluralismo político constitucionalmente garantizado ${ }^{3}$. Esta circunstancia ha influido, no solo en el reparto de la financiación electoral o de los espacios gratuitos para la publicidad, celebración de mítines o mensajes en los medios de comunicación, sino también en el tratamiento de la información electoral por parte de los medios de comunicación. La mediatización de la vida política sigue siendo una constante y resulta innegable que la irrupción de las nuevas formaciones políticas surgidas (como Podemos o Ciudadanos) y su impacto en el escenario político no habría sido posible o, al menos, el mismo, sin la intervención de los medios de comunicación. No ha perdido, desde luego, vigencia la expresión «telecracia» ${ }^{4}$ a la que se refería SARTORI.

El papel de los medios de comunicación sigue siendo crucial pero ha evolucionado con el propio sistema de partidos. En este sentido, es de destacar cómo han cobrado un mayor protagonismo determinados formatos, como los debates plurilaterales «a cuatro», frente debates bilaterales «cara a cara» que hasta ahora habían gozado de mayor interés informativo. Hemos asistido, por lo demás, a una crónica en directo de la vida política por los medios de comunicación, impulsada por los propios actores políticos a través de la convocatoria de ruedas de prensa, en ocasiones simultáneas y en otras sucesivas, para exponer posiciones, acuerdos y desacuerdos ante el proceso de investidura tras las elecciones de diciembre de 2015 y junio de 2016 que pone de manifiesto el rol de los mass media. En este sentido es indudable la contribución de los medios al acercamiento de las formaciones políticas a los ciudadanos y a una mayor «visualización» y «transparencia» del proceso de toma de decisiones políticas 5 .

2 Únicamente se aprobó la LO 2/2016, de 31 de octubre, de modificación de la LOREG, para el supuesto de convocatoria automática de elecciones en virtud de lo dispuesto en el apartado 5 del artículo 99 de la Constitución, que acorta la duración de la campaña electoral (de quince a ocho días), limita más los gastos electorales de los partidos y disminuye la financiación electoral pública de éstos; aunque solo resulta de aplicación para el supuesto específico elecciones convocadas automáticamente en virtud del artículo 99.5 CE, no en el resto de los supuestos de renovación de las Cortes Generales.

3 Véase Azpitarte SánChez, M., «El agotamiento del bipartidismo. Crónica política y legislativa del año 2015», REDC, 106, 2016, pp. 205-232.

4 SArtori, G., Partidos y sistemas de partidos, Alianza Editorial, Madrid, 1999, p. 66.

5 Este es el sentido con el que se ha empleado el término «televización (sic) de lo público», para señalar que la televisión «moviliza las voluntades» (Jiménez DE PARGA, M., La información en la era de la televización de los público, Generalitat de Catalunya, Barcelona, 1997). 
No obstante, sin negar la relevancia de los medios de comunicación como la prensa, la radio y la televisión - a los que la LOREG presta toda su atención-, no puede pasarse por alto el auge e impacto que las «nuevas» (ya no tan nuevas) tecnologías de la información y comunicación (medios digitales, redes sociales, blogs, etc.) han tenido en los últimos años, ofreciendo a los partidos políticos una valiosa vía de difusión de su mensaje y de participación ciudadana, con perfiles y dimensiones que no siempre proporcionan los medios tradicionales. La LOREG, en cambio, no contempla esta realidad, recogiendo una regulación que se muestra en ocasiones desfasada, aún basada en medios tradicionales de publicidad (pegada de carteles, mítines, etc.) y en viejos temores que ven en el ejercicio de la libertad de información un riesgo de coacción sobre la libertad de voto, así como en prohibiciones difíciles de hacer operativas, como la de publicar sondeos los cinco días antes de las elecciones.

La campaña electoral es un momento crucial para dar a conocer los distintos proyectos de gobierno que se concretan en los programas electorales, entre los que la ciudadanía escogerá en función de su ideología y preferencias ${ }^{6}$. Ha de mostrar el pluralismo político existente y permitir el contraste entre las diferentes opciones que se ofrecen a los ciudadanos. Si la información es vital para el funcionamiento de la democracia, en campaña electoral cobra necesariamente una dimensión mayor, puesto que es presupuesto para el ejercicio racional y en libertad del derecho a la participación política. Conscientes de ello y ante el nuevo escenario presentado, se trata de analizar la regulación de la campaña electoral realizada por la LOREG, desde la práctica vivida en los recientes procesos electorales, para poner de manifiesto los puntos más problemáticos y la necesidad de introducir reformas que la adecuen a la realidad de nuestros días.

\section{LA REGULACIÓN DE LOS MEDIOS DE COMUNICACIÓN COMO SOPORTE PARA LA PUBLICIDAD Y EMISORES DE INFORMACIÓN DURANTE LA CAMPAÑA ELECTORAL}

La presencia en los medios, especialmente en la televisión, ha constituido, sin lugar a dudas y al menos hasta ahora, la más importante de las formas que tienen los partidos políticos de dar a conocer su mensaje y solicitar el voto durante la campaña electoral, frente a otras más clásicas como la tradicional «pegada de carteles» o la celebración de mítines. De hecho, estas últimas se siguen llevando a cabo pero con una finalidad mediática, es decir, están concebidas para ser televisadas, o recogidas en imágenes o titulares de prensa. El líder del partido ya no expone su

6 Holgado GonZÁlez, M., El programa de gobierno y sus sistemas de control, Tirant lo Blanch, Valencia, 2008 , p. 33. 
programa político únicamente a los asistentes al mitin, sino que lo hace, sobre todo, dirigiéndose a los telespectadores de los espacios informativos?

Los medios de comunicación constituyen un valioso soporte a través de los cuales los partidos políticos pueden hacer llegar al electorado sus diferentes programas políticos y dar a conocer a las personas que integran sus candidaturas, mediante la inserción de mensajes publicitarios (spots, anuncios en prensa, cuñas radiofónicas, etc.). Pero, siendo este importante, el principal papel de los medios de comunicación durante la campaña es hacer efectivo el derecho de la ciudadanía a recibir información veraz. Nadie discute la dimensión objetiva que tienen las libertades de expresión e información en un sistema democrático, dado que contribuyen a la formación de una opinión pública libre. Pues bien, su significación es si cabe aún mayor cuando se trata de ejercer el derecho al voto dado que para garantizar un ejercicio libre y racional del mismo es esencial contar con información veraz acerca de la realidad social, económica y política en la que vivimos y de las distintas opciones políticas entre las que elegir.

Asumiendo el relevante papel que juegan los medios de comunicación en un momento tan crucial en cualquier sistema democrático, como es el de las elecciones, el legislador ha regulado minuciosamente algunos aspectos de su funcionamiento durante la campaña electoral en la LOREG y en las Leyes Orgánicas reguladoras de la publicidad electoral ${ }^{8}$, con la idea de garantizar el pluralismo político y la igualdad de oportunidades entre todas las formaciones políticas, de modo que la contienda electoral sea lo más justa posible ${ }^{9}$, así como para evitar la arbitrariedad o la opción netamente partidista de un medio de comunicación audiovisual.

Tan alta aspiración se procura lograr principalmente a través de diversas medidas recogidas en estas leyes y que inciden fundamentalmente en esos dos ámbitos a los que nos hemos referido: el de la publicidad electoral y el de la información sobre las elecciones. En este sentido, las medidas se centran en limitar, e incluso prohibir en determinados medios, la contratación de publicidad electoral por parte de los partidos políticos, cediéndoles, en compensación, espacios televisados gratuitos en las emisoras de titularidad pública. De otro lado, traslada a la acción informativa de los medios de comunicación durante las elecciones las exigencias de neutralidad y respeto al pluralismo político, por encima incluso del

7 Avisados de la inmediata conexión en directo durante su intervención (Rallo Lombarte, A., «Debates electorales y televisión», Revista de las Cortes Generales, 44, 1998, p. 67).

8 LO 5/1985, de 19 de junio, del Régimen Electoral General; LO 10/1991, de 8 de abril, reguladora de la publicidad electoral en las emisoras municipales de radiodifusión sonora; LO 14/1995, de 22 de diciembre, reguladora de la publicidad electoral en las emisoras de televisión local por ondas terrestres; LO 2/1988, de 3 de mayo, reguladora de la publicidad electoral en las emisoras de televisión privada, vigente hasta el 30 de enero de 2011 y derogada por la LO 2/2011, de 28 de enero, por la que se modifican distintos aspectos de la LOREG aunque se mantiene el principal contenido de la misma.

9 Vid. SÁNChez muÑoz, O., La igualdad de oportunidades en las competiciones electorales, Centro de Estudios Políticos y Constitucionales, Madrid, 2007. 
criterio periodístico. No entra, en cambio, a regular la celebración de debates electorales televisados, habiendo asumido la Junta Electoral Central la determinación de los criterios a seguir, dando así respuesta a la distinta problemática suscitada en su celebración por las cadenas de televisión privada. Esta regulación tampoco tiene en cuenta, quizás con cierta pereza o ingenuidad normativa, el alcance de las tecnologías de la información y comunicación cuyo uso se ha extendido entre la sociedad y a las que no han sido ajenas las formaciones políticas (redes sociales, blogs, mensajería instantánea, etc.). El hecho de que los medios escritos puedan celebrar debates transmitiendo señal por internet, que los ciudadanos se hagan eco a través de las redes sociales de sondeos publicados en medios de comunicación extranjeros, por señalar algunos ejemplos, pone en evidencia la efectividad de una normativa que quizás no se acomoda bien a las nuevas circunstancias y tenga por ello que ser revisada.

\section{MEDIDAS QUE INCIDEN EN LA PUBLICIDAD ELECTORAL}

\section{III.1. Prohibición/limitación de la contratación de publicidad electoral}

La publicidad es, sin duda, un importante recurso con el que los partidos políticos tratan de darse a conocer y solicitar el voto al electorado. Los medios de comunicación (televisión, prensa, radio) ofrecen un eficaz soporte para ello, que destaca sobre otros más tradicionales para la propaganda (como la colocación de carteles, pancartas o banderolas ${ }^{10}$ ). La regulación restrictiva de la contratación de publicidad electoral en los medios de comunicación trata de evitar que los recursos económicos de los partidos políticos condicionen la igualdad en el acceso a los mismos, hasta el punto de que solo los partidos económicamente fuertes hagan uso de esta publicidad electoral y acaparen el espacio audiovisual durante la campaña. Es evidente que no todas las formaciones políticas cuentan con los mismos ingresos, ni pueden, por tanto, emplear el mismo esfuerzo económico en hacer llegar a los electores su mensaje y su programa a través de la publicidad.

Por esta razón, en España el legislador ha adoptado dos tipos de medidas: de un lado, la prohibición total de contratar publicidad en la televisión y, de otro, la limitación del volumen de gastos que los partidos pueden realizar para contratar publicidad en la prensa y en las emisoras de radio privadas, que en ningún caso podrá superar el veinte por ciento del límite de gasto previsto para los partidos políticos en cada proceso electoral (art. 58.1 LOREG).

Teniendo en cuenta que la publicidad en la televisión es de las más costosas y quedaría por tanto solo al alcance de unos pocos partidos, la prohibición de

10 El art. 55.1 LOREG regula esta fuente de financiación pública indirecta por parte de los Ayuntamientos. 
contratar publicidad en el medio televisivo es absoluta, extendiéndose tanto a los medios de titularidad pública como a las cadenas privadas. La LOREG lo establece de forma clara: «No pueden contratarse espacios de publicidad electoral en los medios de comunicación de titularidad pública ni en las emisoras de televisión privada» ${ }^{11}$.

Tratándose de la prensa escrita y de las emisoras de radio privadas la publicidad electoral se permite, si bien, ha de quedar claro para los lectores y oyentes que se trata precisamente de publicidad, por lo que ha de identificarse como tal para garantizar la correcta información del elector. Además, se prohíbe a estos medios cualquier discriminación entre los distintos candidatos en cuanto a la inclusión, tarifas y ubicación de dichos espacios (art. 58.2 LOREG). Teniendo presente, como es razonable pensar, que cuantos más medios económicos estén a disposición de una fuerza política, en mejores condiciones se hallará para vencer a las demás o para defender sus puntos de vista ${ }^{12}$, con estas medidas se consigue, al menos en este aspecto, la igualdad de condiciones entre todas las formaciones que concurren a las elecciones.

Precisamente en aras de la igualdad y en el contexto de la crisis económica de los últimos años, el legislador español ha reducido el período de tiempo en que puede contratarse publicidad en estos medios: únicamente durante los quince días que dura la campaña electoral ${ }^{13}$. La clave para determinar el umbral de lo permitido por la LOREG fuera de la campaña electoral, de acuerdo con la interpretación de la JEC, se encuentra en la existencia de algún tipo de contratación comercial, por eso no se permite «la inserción de anuncios en prensa o revistas, o en cuñas radiofónicas, o en formatos publicitarios en Internet («banners») o en canales comerciales de televisión, o en otros soportes en medios digitales», pero sí está permitida «la creación o utilización de páginas o sitios web de recopilación de textos o artículos (blogs) de las formaciones políticas o de los candidatos, o la participación en redes sociales (Facebook, Twitter, Tuenti, etc.)» ${ }^{14}$.

La justificación de esta intervención por parte del legislador, restringiendo las posibilidades de contratar publicidad electoral y afectando en cierto modo a la libertad de expresión (art. 20.1.a) CE), se encuentra en la igualdad en el ejercicio del derecho de participación política y acceso a los cargos públicos que nuestra Constitución garantiza (art. 23 CE), entendida bajo el mandato del artículo 9.2

11 Art. 60 LOREG, en la redacción dada por la LO 2/2011, de 28 de enero, incorporando la prohibición que ya se recogía en la Ley Orgánica 2/1988, de 3 de mayo, reguladora de la publicidad electoral en las emisoras de televisión privada.

12 Lucas Murillo de la Cueva, P., «La financiación de los partidos políticos», Anuario de Derecho Constitucional y Parlamentario, 5, 1993, pp. 103-193.

13 Art. 53.2 LOREG: «desde la convocatoria de las elecciones hasta el inicio legal de la campaña, queda prohibida la realización de publicidad o propaganda electoral mediante (...) inserciones en prensa, radio u otros medios digitales», en la redacción dada por la LO 2/2011, de 28 de enero.

14 Instrucción de la JEC 3/2011, de 24 de marzo, sobre interpretación de la prohibición de realización de campaña electoral incluida en el artículo 53 de la LOREG. 
CE y en directa conexión con el pluralismo político, indispensable para que se den unas elecciones justas y verdaderamente democráticas.

\section{III.2. La cesión de espacios gratuitos o el llamado derecho de antena}

La prohibición de contratar publicidad en el medio televisivo viene contrarrestada por el derecho a disponer de espacios gratuitos en las cadenas públicas. Un derecho que ha sido calificado como una suerte de «indemnización normativa frente a la expropiación del derecho de libertad de expresión» ${ }^{15}$. No podía ser de otro modo puesto que el acceso de las formaciones políticas a los medios de comunicación de titularidad pública está garantizado constitucionalmente a los «grupos políticos significativos» (art. 20.3 CE), siguiendo el ejemplo de la Constitución portuguesa $^{16}$.

Para poder acceder a los espacios gratuitos en las emisoras de radio y televisión de titularidad pública los partidos tienen que cumplir el requisito de haber presentado candidaturas en un número determinado de circunscripciones electorales, que varía en función del ámbito de las elecciones en cuestión (generales $^{17}$, municipales ${ }^{18}$, europeas ${ }^{19}$, autonómicas ${ }^{20}$ ). El acceso a los medios de comunicación queda asegurado, por tanto, a prácticamente todas las formaciones políticas, estén o no representadas en el Parlamento, evitando que la oferta electoral mostrada en los mass media se reduzca a los dos o tres partidos más significativos. Y ello contribuye en alguna medida a la movilidad del sistema de partidos, permitiendo a las formaciones nuevas o que no alcanzaron representación en elecciones anteriores, darse a conocer y difundir su mensaje a través de medios con notoria repercusión como son la radio y la televisión. Hay algunos autores que consideran, no obstante, que las actuales condiciones para beneficiarse de estos espacios gratuitos son extremadamente generosas por haber permitido a partidos ficticios utilizar estos espacios con fines distintos a los electorales, "produciendo con ello, al margen de un claro fraude de ley, una sobresaturación de tiempos de propaganda electoral, que acaban perjudicando

15 ZACCARIA, R., Radiotelevisione e costituzione, Milano, 1977.

16 El primer reconocimiento constitucional del derecho a acceder a los medios de comunicación se encuentra en la Constitución portuguesa de 2 de abril de 1976, cuyo art. 40.2 establece que «en época de elecciones los partidos políticos concurrentes tendrán derecho a períodos de emisión regulares y equitativos». LOREG).

17 El 75\% de las circunscripciones comprendidas en el ámbito de difusión del medio (art. 64.2

18 Municipios que representen el 50 por 100 de la población de las circunscripciones incluidas en el ámbito de difusión del medio (art. 188 LOREG).

19 Al ser una circunscripción única, todos los partidos que concurren a las elecciones tienen derecho a espacios gratuitos.

20 Se aplica supletoriamente lo dispuesto para las elecciones generales cuando la Comunidad Autónoma no haya dispuesto algo distinto en su legislación electoral. 
a las auténticas candidaturas y en definitiva al conjunto del electorado» ${ }^{21}$. Por este motivo sugieren endurecer estos requisitos o exigir una fianza a los partidos que concurran a las elecciones, fianza que sería devuelta después de haber obtenido un número determinado de $\operatorname{votos}^{22}$. No obstante, no parece conveniente que para evitar su posible utilización fraudulenta se ponga obstáculos a quienes legítimamente pretenden hacer un correcto uso de ellas, teniendo en cuenta que exigir fianzas a pequeños partidos o a nacientes formaciones políticas los colocaría en una clara situación de desventaja frente a partidos ya consolidados que cuentan con suficientes fondos económicos. Estamos ante una modalidad de financiación pública indirecta que los partidos reciben precisamente para asegurar la igualdad de oportunidades en la contienda electoral, dadas las funciones que tienen constitucionalmente encomendadas ${ }^{23}$.

La igualdad en el acceso a los medios de comunicación se va a traducir en proporcionalidad, atendiendo al respaldo electoral recibido en anteriores elecciones equivalentes. Este también llamado por algunos «derecho de antena» ${ }^{24}$ consiste en unos tiempos reservados en las emisoras de radio y televisión públicas para cada partido, y que se distribuyen en cuatro franjas en función del número de votos obtenido en elecciones anteriores equivalentes: diez, quince, treinta y cuarenta y cinco minutos ${ }^{25}$. Sería deseable en este sentido una reforma que ajustase mejor, desde el punto de vista de la proporcionalidad, la distribución de estos espacios al criterio base recogido en el artículo 61 LOREG $^{26}$. Las distintas Comunidades Autónomas han seguido un criterio similar a la hora de conceder espacios a los partidos en los medios de comunicación de titularidad pública dentro de su ámbito territorial de difusión (ya sean medios de la respectiva Comunidad, o medios nacionales en la programación regional).

La distribución de estos espacios gratuitos la lleva a cabo la Junta Electoral Central a la vista de la propuesta realizada por una Comisión de Radio y Televisión de la que forman parte representantes de los partidos políticos con escaño

21 Santolaya Machetti, P., Manual de procedimiento electoral, Ministerio del Interior, Madrid, 1995, p. 99.

22 Pajares Montolío, E., La financiación de las elecciones, Congreso de los Diputados, Madrid, 1998, p. 93.

23 Holgado GonzÁlez, M., La financiación de los partidos políticos en España, Tirant lo Blanch, Valencia 2003 , p. 92.

24 García Llovet, E., «El derecho de antena y las campañas electorales», RDP, 25, 1987, pp. $151-181$

$25 \mathrm{El}$ art. 64.1 LOREG establece un derecho de diez minutos para los partidos que no concurrieron o no obtuvieron representación en elecciones anteriores equivalentes, quince minutos para los que alcanzaron el 5 por 100 de los votos, treinta minutos para los que obtuvieron entre el 5 y el 20 por 100 de los votos y cuarenta y cinco minutos para los que alcanzaron, al menos, un 20 por 100 del total de votos válidos emitidos. Estos espacios se verían reducidos en un cincuenta por ciento en el supuesto de elecciones convocadas por la disolución automática de acuerdo con el art. 99.5 CE, según establece la Disposición Adicional $7^{\mathrm{a}}$ de la LOREG incorporada por la LO 2/2016, de 31 de octubre.

26 En el mismo sentido se ha pronunciado el Consejo de Estado (Informe del Consejo de Estado sobre las propuestas de modificación del régimen electoral general, de 24 de febrero de 2009). 
en el Congreso de los Diputados, participando con un voto ponderado ${ }^{27}$. Su tarea consiste en distribuir entre los distintos partidos los espacios gratuitos reservados en las emisoras de radio y televisión públicas para la emisión de mensajes electorales, y lo hace aplicando los criterios establecidos por la ley, y atendiendo a las preferencias de los partidos mayoritarios ${ }^{28}$. La JEC es el órgano decisor y puede aceptar la propuesta de la Comisión de Radio y Televisión, modificarla en los aspectos que estime oportuno o resolver las discrepancias habidas en su seno. Tratándose de la programación regional o local de estos medios públicos, la JEC puede, y, de hecho, así viene haciéndolo, delegar su competencia en las Juntas Electorales Provinciales que nombrarán una Comisión, con las mismas funciones y composición, en el ámbito territorial de que se trate.

Los partidos políticos gozan de libertad a la hora de establecer el formato y el contenido del mensaje con el que ocupar estos espacios gratuitos para presentar al electorado su candidatura y su programa, con el requisito, eso sí, de pedir el voto a los electores y con la única limitación de su duración ${ }^{29}$.

\section{EL TRATAMIENTO DE LA INFORMACIÓN POLÍTICA EN CAMPAÑA ELECTORAL}

La principal función de los medios de comunicación, como creadores y emisores de información en el período electoral, es abordada por la LOREG de forma bastante parca si la comparamos con la atención prestada a la contratación de publicidad electoral y a la imposición de espacios gratuitos para que los partidos pidan el voto en los mismos. El legislador ofrece así una visión que se acerca más a la idea del «consumidor» que a la del «ciudadano» ${ }^{30}$, al poner el acento en los medios de comunicación como instrumento o lugar para la propaganda política. Y no en la información sobre elecciones que es elaborada por los propios medios de comunicación y que «goza de mayor capacidad de influencia en la formación de la opinión pública en tanto se presume su imparcialidad, objetividad y veracidad» ${ }^{31}$. A nadie se oculta que mientras que los ciudadanos apenas reparan en los espacios electorales cedidos obligatoriamente a los partidos, sí siguen con mayor interés los programas de carácter informativo tanto en televisión como en radio

27 Art. 65.3 LOREG.

28 Art. 65.2 LOREG.

29 La JEC ha negado el derecho a estos espacios gratuitos a las formaciones políticas que propugnen en ellos la abstención, como fue el caso de EH que pretendía utilizar los espacios de propaganda electoral con el lema «En el camino de la autodeterminación: la abstención» (Acuerdo de la JEC 169/2000, de 21 de febrero).

30 Arnaldo Alcubilla, E., «Procesos electorales y opinión pública», Revista de las Cortes Generales, 34, 1995, p. 175.

31 Rallo Lombarte, A., 1998, op. cit., p. 67. 
(telediarios, entrevistas, debates, etc.) así como la cobertura de la campaña electoral realizada por la prensa escrita ${ }^{32}$.

La escasa regulación del tratamiento de la información electoral no debe llevarnos a error. Esta parquedad y silencio en muchas cuestiones no equivale a maximizar automáticamente la libertad de información. Es cierto que no hay mención en la ley a los debates televisados y tampoco se abordan con detalle las diferentes formas en que se muestra la información sobre elecciones. Pero en los dos únicos preceptos ${ }^{33}$ dedicados a ésta, uno para exigir neutralidad y pluralismo político en su tratamiento y otro para regular la publicación de sondeos electorales, se muestra claramente que no se ha optado en la LOREG por una mínima intervención en el ejercicio de la libertad de información de los medios de comunicación. Y la interpretación y necesaria concreción llevada a cabo por la JEC de manera casuística, así lo corrobora, puesto que aunque no quepa hablar de «estado de excepción informativo» ${ }^{34}$, sí se van a permitir distintos grados de intensidad en el control del tratamiento de la información durante la campaña electoral dependiendo del medio de comunicación (televisión, radio o prensa escrita), de la titularidad (pública o privada), del tipo de información (general, específicamente electoral) y del formato (informativos, entrevistas, debates, sondeos electorales).

\section{IV.1. Información general y sobre elecciones}

El legislador ha tenido en cuenta el desigual impacto de los distintos medios de comunicación (prensa, radio, televisión) sobre la ciudadanía, para modular el grado de intervención en el tratamiento de la información elaborada y difundida por estos. Así, la intensidad de dicha intervención alcanza el nivel más alto tratándose del medio televisivo, al que se reconoce el mayor impacto por su carácter audiovisual, siendo por lo demás la principal fuente de información a la que acuden los ciudadanos durante la campaña ${ }^{35}$. A las cadenas de televisión se les exige

32 En esta línea de la preferencia ciudadana por la información frente a la propaganda, del 67\% de los españoles que reconocen utilizar Internet, el 40.2\% siguen la información electoral a través de las páginas web de los medios digitales (prensa y radio) frente al $7.4 \%$ que declara haber consultado la web de los partidos y candidatos. Barómetro Postelectoral del CIS, julio 2016, Estudio 3145, disponible en http://www.cis.es/cis/ export/sites/default/-Archivos/Marginales/3140_3159/3145/es3145mar.pdf

33 Arts. 66 y 69 LOREG, obviando el art. 68 LOREG que solo contiene algunas especialidades en el ejercicio del derecho de rectificación por la información inexacta publicada sobre candidatos o dirigentes de partidos y demás formaciones políticas concurrentes a las elecciones.

34 Empleando la expresión de García Mahamut, R. Rallo Lombarte, A., «Neutralidad y pluralismo en los medios de comunicación en las campañas electorales. La reforma de la LOREG de 2011», Revista Española de Derecho Constitucional, 98, 2013, p. 238, en el mismo sentido.

35 El $50.8 \%$ de los españoles reconocieron haber seguido la información política de las elecciones generales de 2016 a través de la televisión, frente al 19.8\% que para ello acudió a la prensa escrita y el $17.5 \%$ que la siguió por la radio. Barómetro Postelectoral del CIS, julio 2016, Estudio 3145, disponible en http:// www.cis.es/cis/export/sites/default/_Archivos/Marginales/3140_3159/3145/es3145mar.pdf 
no solo respetar el pluralismo político y la igualdad - como ocurre con las emisoras de radio_- , sino incluso la proporcionalidad y neutralidad en la programación informativa; mientras que la prensa escrita no se ve compelida por ninguno de estos principios durante el período electoral ${ }^{36}$.

En cumplimiento de la función pública que los medios de comunicación dependientes del Estado deben desempeñar, de acuerdo con el artículo 20.3 CE, también se modula el tratamiento de la información teniendo presente la titularidad pública o privada de los medios. A todas las cadenas tanto de radio como de televisión de titularidad pública, el artículo 66 LOREG y la Instrucción 4/2011 de la JEC que desarrolla sus previsiones les exigen el cumplimiento de los principios de igualdad, pluralismo político, proporcionalidad y neutralidad informativas. El respeto al pluralismo político es un mandato impuesto a los medios de comunicación públicos en la misma Constitución (artículo 20.3 CE), cobrando mayor sentido su exigencia durante el proceso electoral, en el que se debe garantizar la igualdad en el acceso a los cargos públicos (artículo $23 \mathrm{CE}$ ). Una igualdad que ha de traducirse en proporcionalidad, dedicando a cada formación política un tiempo determinado en función de los resultados alcanzados «en las últimas elecciones equivalentes celebradas», de acuerdo con la citada Instrucción 4/2011. Esta proporcionalidad se va a concretar en tres niveles cuantitativos, desde el punto de vista del tiempo dedicado a la información específica electoral de las siguientes formaciones políticas: a) unos tiempos superiores para las formaciones políticas que alcanzaron representación en las anteriores elecciones equivalentes; b) unos tiempos mínimos asegurados para las formaciones con la consideración de «grupos políticos significativos» ${ }^{37}$, que no podrán superar en ningún caso a las fuerzas políticas con representación; y c) la posibilidad de dedicar tiempos para las demás fuerzas políticas siempre que no superen al dedicado a los grupos políticos significativos. La medición de dichos resultados electorales puede hacerse en base al criterio que libremente adopte el medio en cuestión, ya que la Instrucción no lo ha fijado (votos o escaños) ${ }^{38}$. Este criterio servirá igualmente para determinar el orden de aparición en la información electoral específica ofrecida por los medios, mostrándose en primer lugar los partidos que obtuvieron mayores

36 La única referencia a la información política durante la campaña electoral la encontramos en el art. 66 LOREG, regulación a la que se remite a su vez el art. 26 del Estatuto de la Radio y la Televisión.

37 Figura acuñada por la Instrucción de la JEC 1/2015, de 15 de abril, de modificación de la Instrucción 4/2011, para referirse a «formaciones políticas concurrentes a las elecciones que, pese a no haberse presentado en las anteriores elecciones equivalentes o no haber obtenido representación en ellas, con posterioridad, en recientes procesos electorales y en el ámbito territorial del medio de difusión, hayan obtenido un número de votos igual o superior al $5 \%$ de los votos válidos emitidos». Una valoración positiva de la solución dada por la JEC con esta figura a la irrupción de nuevas formaciones políticas a las campañas electorales de 2015 y 2016 puede verse en Fernández De Casadevante Mayordomo, P., 2016, op. cit.

38 Acuerdos de la JEC 124/2016, de 8 de junio; 110/2004 de 16 de febrero y 134/2004, de 23 de febrero y 162/2006, de 11 de octubre (confirmados por SSTS de 10 de noviembre de 2004 y 2 de octubre de 2006, respectivamente). 
resultados seguidos del resto de mayor a menor ${ }^{39}$. Finalmente, los medios públicos deben respetar el principio de neutralidad informativa, esencial para el normal desarrollo de la campaña electoral y que, de acuerdo con la Ley de la Radio y de la Televisión de Titularidad Estatal, es uno de los principios inspiradores de su actividad («información objetiva, veraz y plural» ${ }^{40}$ ). Y desde luego es incuestionable que estos deben hacer una adecuada cobertura informativa de la campaña electoral, dada la relevancia pública de las elecciones, desde el punto de vista del derecho de la sociedad a recibir información ${ }^{41}$.

Para garantizar el cumplimiento de estos principios en los medios de comunicación públicos se establece un control preventivo que obliga a sus órganos de dirección a poner en conocimiento de las Juntas electorales correspondientes, con la debida antelación, los denominados «Planes de Cobertura Informativa de la campaña electoral», en los que habrán de incluir «los debates, entrevistas y programas específicos de naturaleza electoral que pretendan realizar, así como los criterios sobre la información específica relativa a la campaña electoral» ${ }^{42}$. La finalidad de este control previo es dar oportunidad a los representantes de las distintas candidaturas de recurrir dichos Planes en el plazo que la Junta Electoral determine a fin de minimizar los efectos que pudiera tener un eventual tratamiento arbitrario o partidista de la información electoral y poder, de este modo, establecer los cambios que respeten dichos principios.

El control del cumplimiento por los medios de comunicación privados de los principios de igualdad y pluralismo (para las emisoras de radio) a los que se suman los de neutralidad y proporcionalidad (para las cadenas de televisión) en su información específica sobre elecciones ${ }^{43}$, es un control reparador o a posteriori. Los medios privados no tienen que dar a conocer con antelación el plan de su programación informativa a las Juntas Electorales, pero los candidatos y formaciones políticas concurrentes a las elecciones podrán recurrir tales programas una vez emitidos, cuando consideren que no han respetado la igualdad y el pluralismo político, en cuyo caso se procederá a la medida compensatoria adecuada cuando sea posible ${ }^{44}$. La Junta Electoral Central también ha modulado la exigencia de

39 Acuerdo de la JEC 120/2008, de 27 de febrero estableciendo que la JEC puede controlar los tiempos y el orden de aparición de las candidaturas en los Planes de Cobertura, confirmado por el Tribunal Supremo, que considera que se trata de aspectos externos (tiempos, orden de mayor a menor) que no inciden en el contenido de la información (que compete a los periodistas) por lo que no hay violación del artículo 20.1.a) CE siendo la JEC responsable de garantizar el respeto al pluralismo político y social y la neutralidad informativa (STS de 19 de octubre de 2009).

40 Art. 3.3.b) de la Ley 17/2006, de 5 de junio, de la Radio y de la Televisión de Titularidad Estatal.

41 García llovet, E., op. cit.

42 Apartado 4.1 de la Instrucción 4/2011, de 24 de marzo, de la JEC.

43 Dejando a un lado la organización de debates electorales, que sí debe ser comunicada con antelación a la Junta electoral, como veremos más adelante.

44 Aunque a veces solo quepa dictar resoluciones con valor meramente declarativo, como en el caso del recurso planteado contra el programa de la Sexta Noche en el que participaron expertos y periodistas, centrándose únicamente en las cuatro formaciones más votadas, en la jornada de reflexión, sin posibilidad material de 
proporcionalidad en el caso de los medios privados, a los que se insta a atender «preferentemente» a los resultados en las últimas elecciones equivalentes, sin que se lleve a cabo un estricto control de una proporcionalidad aritmética, sino «prudencial» ${ }^{45}$, asegurando que la información sea proporcionada «con arreglo a un criterio ponderadamente proporcional a tales resultados» ${ }^{46}$.

La Junta Electoral Central también ha diferenciado el tratamiento de la información según se trate de información política de carácter general o información específica sobre elecciones, —quedando fuera los programas de entretenimiento por más que pudieran tener incidencia electoral ${ }^{47}$ - extremando la exigencia del principio de igualdad y proporcionalidad en la información específica. Tratándose de la información general, a la Junta Electoral «no le es posible sustituir a los profesionales de los medios en la valoración de lo que en cada momento sea noticia, ya que esta decisión corresponde a la libertad de información de estos ${ }^{48}$, aunque ha instado a la televisión pública a evitar que la información sobre la actividad del gobierno, unida a la del partido político que lo apoya, no suponga una diferencia importante en cuanto al minutaje del resto de las formaciones políticas ${ }^{49}$. En todo caso, y siempre que se trate de información política general, no se puede apreciar la vulneración de los principios de neutralidad y proporcionalidad a partir de «una noticia aislada sino en relación a un ámbito temporal más amplio» ${ }^{50}$. En cambio, la información específica sobre elecciones que se emite diariamente en los informativos televisados (la llamada «crónica río») sí es objeto de un control más intenso por parte de la Junta Electoral, procediéndose a una comprobación de la proporcionalidad «diariamente y en los correspondientes informativos del medio» ${ }^{51}$.

De todo lo expuesto, cabría distinguir, por tanto, cuatro niveles de intensidad en la intervención estatal sobre la información electoral de los medios de comunicación: a) Un nivel máximo, que alcanza a la radio y televisión pública, a los que se exige el respeto a los cuatro principios con un control previo o preventivo y una estricta aplicación de la proporcionalidad aritmética en los tiempos y

que la JEC adoptase medidas para compensar al resto de candidaturas a pesar de considerar que se había vulnerado el principio de pluralismo político (Acuerdo de la JEC 202/2016, de 26 de junio).

45 García Mahamut, R. y Rallo Lombarte, A., op. cit., p. 227.

46 Acuerdo de la JEC 33/2005, de 25 de enero. Criterio consolidado finalmente en la Instrucción de la JEC 4/2011.

47 A los que no son de aplicación los principios de neutralidad y proporcionalidad. Acuerdos de la JEC 571/2015, de 9 de diciembre (El Hormiguero) y 568/2015, de 9 de diciembre (En la tuya o en la mía), sobre programas a los que no se había invitado al candidato de UPyD.

48 Acuerdos de la JEC 208/2004, de 8 de marzo, 714 y 715/2011, de 16 de noviembre y 602/2015, de 17 de diciembre, entre otros.

49 Acuerdo de la JEC 509/2015, de 2 de diciembre.

50 Acuerdo de la JEC 602/2015, de 17 de diciembre. Por eso, se respeta la neutralidad y proporcionalidad aunque dos días se haya excluido a la formación UPyD en los espacios informativos de Antena Tres (Acuerdo de la JEC 598/2015, de 15 de diciembre).

51 Acuerdo de la JEC 133/2008, de 3 de marzo. 
orden de emisión; b) Un nivel intermedio, que se aplica a la televisión privada, a la que se exige el respeto a los mismos principios, pero con un control posterior y una aplicación de la proporcionalidad no aritmética sino ponderada; c) Un nivel atenuado, que rige para las emisoras de radio privadas, a las que se exige únicamente el respeto a los principios de igualdad y pluralismo político, con un control posterior, sin que sea de aplicación la proporcionalidad; y finalmente c) Un nivel mínimo, para la prensa escrita, que goza de mayor libertad de información y únicamente se sujeta a las especialidades del derecho de rectificación en el caso de información inexacta y a la regulación de la publicación de sondeos electorales, como se verá más adelante.

La necesidad de una intervención tan intensa de la información electoral en los medios de titularidad pública ha sido puesta en duda por los profesionales de la comunicación, contrarios a la imposición de tiempos cronometrados y de un orden fijado en función de los resultados electorales, frente al criterio periodístico que debería determinar lo que es noticiable o no. Los Consejos de Dirección de los Informativos de la Radio y Televisión Públicas han reivindicado en numerosas ocasiones la independencia de los profesionales de la comunicación y el criterio periodístico para garantizar de forma auténtica la neutralidad y objetividad de la información ${ }^{52}$.

Para justificar tal limitación de la libertad de información y la exigencia de neutralidad en campaña electoral a los medios públicos ha de existir una causa jurídica suficientemente relevante. Y esa causa legitimadora es precisamente el ejercicio por los ciudadanos del derecho al sufragio — «nervio y sustento de la democracia ${ }^{53}$ - , que ha de ser universal, igual, directo, secreto y además libre (art. 68.1 CE). Una libertad que no se garantiza únicamente por la ausencia de cualquier tipo de coacción en su ejercicio, sino que exige que el elector disponga de la información necesaria acerca de la oferta electoral (partidos que concurren a las elecciones, candidatos, programas de gobierno, etc.). Por ello, el Estado ha de velar por hacer posible unas elecciones libres y competitivas, realizadas en términos de auténtica concurrencia, «sin ventajas ni privilegios institucionales para nadie» ${ }^{54}$, y por eso la Radio y Televisión públicas, de acuerdo con los intereses generales, deben ofrecer una información electoral que, además de veraz, sea

52 Comunicado de los Consejos de Informativos de TVE, RNE y RTVE.ES, de 24 de mayo de 2016, dirigido a la JEC en el que se denuncia que «la Corporación RTVE faltó a sus compromisos de neutralidad informativa, mostrando a la sociedad española una información manipulada y alejada de los valores democráticos. Sirva, a modo de ejemplo, la presencia informativa dada a grupos políticos significativos como PODEMOS y CIUDADANOS en el reparto de tiempos de los Telediarios de TVE (emisiones TD1 y TD2) de los días 4, 5, 6, 7 y 8 de diciembre. Ambas fuerzas políticas tuvieron, sumadas, una presencia del 2\% del tiempo total. El desequilibrio informativo, según registraron distintos análisis de algunas de las organizaciones representadas en este escrito, siempre operaba en favor del partido en el gobierno».

53 STC 24/1990, de 15 de febrero, FJ. $2^{\circ}$.

54 Solozábal Echavarría, J. J., «Una visión institucional del proceso electoral», REDC, 39, 1993, p. 67. 
completa, sin dejar fuera a los grupos políticos significativos que concurren a las elecciones, de acuerdo con el artículo 20.3 CE. Tal limitación entraría por tanto dentro de la previsión constitucional según la cual las libertades de expresión e información «tienen su límite en el respeto a los derechos reconocidos en este Título» (art. 20.4 CE), a saber, el derecho a participar en los asuntos públicos y a acceder en condiciones de igualdad a las funciones y cargos públicos (art. $23 \mathrm{CE}$ ). Así se ha admitido por la mayoría de la doctrina, llegando incluso a considerar la regulación de la LOREG «plausible» en este ámbito dadas la dificultades de un sistema basado exclusivamente en criterios estrictamente periodísticos, mientras no se despoliticen los medios de comunicación de titularidad pública (no por desconfiar de los profesionales de la comunicación sino de los órganos de dirección de los entes públicos) ${ }^{55}$.

Lo cierto es que la aplicación a los medios públicos de estos principios de neutralidad e igualdad entendida como proporcionalidad implica que la estructura de los programas informativos se formule en bloques cronometrados, en función de los resultados electorales alcanzados por los partidos políticos en elecciones equivalentes anteriores, de forma similar a como están regulados los espacios electorales gratuitos. Esta aplicación estricta y no ponderada del principio de proporcionalidad, «cronómetro en mano», ha dado como resultado una reiteración de dicha estructura de bloques de publicidad electoral en el ámbito de la información electoral en los medios televisados ${ }^{56}$, cuando los tiempos en la información electoral no tendrían que ser una proyección exacta de los espacios gratuitos. No estamos ante propaganda electoral sino ante programas de naturaleza informativa, por eso se ha defendido por alguna doctrina que «la determinación de su contenido y realización debería corresponder a empresas de gestión de los servicios de Radio y Televisión» ${ }^{57}$. Sería al menos planteable, por ser más respetuoso con la libertad de información, la posibilidad de optar por un control posterior y no preventivo, suprimiendo la obligación de comunicar por adelantado los Planes de Cobertura Informativa y hacer una aplicación de la proporcionalidad no tan aritmética, sino ponderada.

Si la limitación de la libertad de información podría ser discutible en los medios públicos, mayores son las dudas de constitucionalidad de la exigencia de la neutralidad y proporcionalidad en el tratamiento de la información electoral

55 Fernández de Casadevante Mayordomo, P., «Los nuevos grupos políticos significativos en la cobertura informativa electoral», Revista Vasca de Administración Pública, 105, 2016, p. 151. En este sentido, Bustos Gisbert pone el acento en la presión ejercida por los partidos políticos, representados en los Consejos de Administración de los Entes Públicos de la Radio y Televisión, que imponen una excesiva rigidez en la aplicación del criterio igualdad-proporcionalidad y un incorrecto entendimiento de la neutralidad informativa que vacía de criterio profesional a los espacios informativos (BusTOS GISBERT, R., «La intervención estatal en los medios de comunicación: la garantía del pluralismo e independencia de los medios», Comunicación y cultura, 3, 1998, p. 93).

56 En el mismo sentido, SÁNCHEz MuÑoz, O., op. cit., p. 261.

57 García Llovet, E., op. cit., p. 172. 
por parte de los medios televisivos privados, al no contar con el apoyo constitucional del artículo 20.3 CE. Y así lo ha puesto de manifiesto buena parte de la doctrina por considerar una intervención excesiva del Estado en el ejercicio del derecho a la libertad de información de medios privados, que lícitamente pueden tener una línea editorial propia en ejercicio de su libertad ideológica (art. 16 CE) y de empresa (art. $38 \mathrm{CE})^{58}$.

Está claro que el fin que persigue esta "publificación» ${ }^{59}$ del estatuto jurídico de la televisión privada durante el proceso electoral es el de garantizar la igualdad de oportunidades de las distintas formaciones políticas que concurren en las elecciones y, en suma, una justa competitividad entre todas ellas. Pero tan loable fin no puede hacerse a costa de sacrificar tan intensamente un derecho fundamental como el de la libertad de información, sin incurrir en desproporcionalidad. Precisamente estas dudas de constitucionalidad revisten más fundamento tratándose de un derecho que trasciende al simple ejercicio individual por parte del profesional, porque, como ha reconocido el Tribunal Constitucional, las libertades de expresión e información constituyen «garantía de la opinión pública libre, que es una institución ligada de manera inescindible al pluralismo político, valor esencial del Estado democrático, estando estas libertades dotadas por ello de una eficacia que trasciende a la común y propia de los demás derechos fundamentales» ${ }^{60}$. Por ello, gran parte de la doctrina se ha mostrado contraria a la exigencia del principio de neutralidad a las cadenas de televisión privadas por considerar que tal obligación afecta al contenido esencial de la libertad de información e ignora la línea editorial que pueden tener los medios de comunicación privados, creando «una ficción en base a la cual las televisiones privadas carecerían de ideología y, por extensión, de línea editorial ${ }^{61}$.

Hay que tener en cuenta que las circunstancias que pudieran haber aconsejado esta equiparación de los medios televisivos privados a los públicos en un primer momento $^{62}$, con un número muy reducido de cadenas de televisión de innegable impacto e incidencia electoral frente a los otros medios de comunicación existentes

58 Solozábal Echavarría, J. J., op. cit., p. 76; Martínez Sospedra, M., «La financiación de los partidos políticos. Ensayo de aproximación», Cuadernos Constitucionales de la Cátedra Fadrique Furió Ceriol, 11/12, 1995, p. 29; SANTOlaya MaChetTi, P., «Algunos problemas de la regulación de las campañas electorales», Corts: Anuario de derecho parlamentario, 24, 2010, p. 274; Delgado-Iribarren García-Campero, M., «La reforma electoral en ciernes: a propósito del informe sobre la reforma electoral aprobado por la Comisión Constitucional del Congreso de los Diputados el 30 de junio de 2010», Corts: Anuario de derecho parlamentario, 24, 2010, p. 57; Fernández de Casadevante Mayordomo, P., 2016, op. cit., p. 161.

59 Solozábal Echavarría, J. J., op. cit., p.78. Expresión también utilizada por García Mahamut, R. y Rallo Lombarte, A. (op. cit., p. 217), aunque a favor de la opción realizada por el legislador, al considerar el valor propagandístico que tiene para el partido político su intervención o aparición en el medio televisivo, «tratándose de un acto más de campaña».

60 STC 121/1989, de 3 de julio, FJ. $2^{\circ}$. Vid. por todas STC 6/1981, de 16 de marzo, FJ. $3^{\circ}$, STC 104/1986, de 17 de julio, FJ. 5 ${ }^{\circ}$, STC 165/1987, de 27 de octubre, FJ $10^{\circ}$ y STC 107/1988, de 8 de junio, FJ $2^{\circ}$.

61 Fernández de Casadevante Mayordomo, P., 2016, op. cit., p. 161.

62 Visión publicista de Rallo Lombarte, A., Pluralismo informativo y Constitución, Tirant lo Blanch, Valencia, 2000, que también defendimos en otro trabajo (Holgado González, M., 2003, op. cit., p. 90). 
(prensa escrita, radio), han cambiado sustancialmente. La proliferación de cadenas de televisión privadas con la generalización de la televisión digital y, sobre todo, la existencia de otras formas de comunicación de carácter audiovisual (prensa digital, redes sociales, Internet, blogs, etc.) que se hacen eco de las primeras y muchas veces las contrastan, ofrecen al electorado un amplio abanico de posibilidades con el que satisfacer su derecho a recibir información y ejercer con libertad su voto. Precisamente la generalización de las tecnologías de la información y comunicación ha contribuido, con esa apertura de cauces a disposición de los ciudadanos, a que estos sean más conscientes de que el pluralismo político se ve igualmente reflejado en una pluralidad de medios de comunicación con líneas editoriales diferentes, que lejos de suponer un riesgo para la efectividad de tal principio, contribuyen a formar una opinión pública libre. El grado de influencia de la televisión, aunque siga siendo el medio más utilizado por la ciudadanía para informarse, no es el mismo que entonces, sino que se ve contrarrestado por la existencia de una pluralidad de cadenas y de otros medios, sin que los ciudadanos ignoren el distinto enfoque o línea editorial de los mismos, como sucede con la prensa escrita y medios digitales.

Por todo ello, el actual contexto nos permite adoptar una posición restrictiva de tales límites a la libertad de información, que, además de cuestionar la madurez de la ciudadanía, no se muestran tan necesarios para asegurar la igualdad de armas en la contienda electoral, desde el punto de vista de la proporcionalidad exigida a cualquier limitación de los derechos fundamentales de acuerdo con la doctrina del Tribunal Constitucional. Que sean, por tanto, criterios exclusivamente periodísticos los que guíen la elaboración de la programación informativa en las cadenas de televisión privadas, como ocurre con las emisoras de radio privadas y la prensa escrita. En este sentido, hay que señalar que en España los periodistas se han mostrado claramente contrarios a esta regulación que les obliga a establecer bloques informativos cronometrados, que no solo vulnera la libertad de información de los medios privados, sino que además reduce el interés periodístico para la ciudadanía ${ }^{63}$.

Pero también cabría aportar otra razón más, la de la dudosa eficacia de tales medidas que tratan de garantizar la igualdad y neutralidad en base a elementos meramente cuantitativos (tiempos, orden de emisión) y que pueden ser fácilmente eludibles a través de un diferente tratamiento cualitativo que favorezca o perjudique a una candidatura (y posibilidades de hacerlo sin incurrir en una burda vulneración del pluralismo político hay muchas). Sería conveniente, por

63 Escrito de la Federación de Asociaciones de Periodistas de España (FAPE), de 10 de febrero de 2011, dirigido a la Defensoría del Pueblo para que interpusiera un recurso de inconstitucionalidad contra la LO 2/2011 que imponía bloques de información electoral a las televisiones privadas, con reparto proporcional de los tiempos de los partidos, conforme a los resultados obtenidos en las anteriores elecciones. Véase el Manifiesto de la Federación de Asociaciones de Periodistas de España contra las ruedas de prensa sin preguntas y otras anomalías informativas \#sinpreguntasnocobertura, de 5 de mayo de 2011. 
tanto, una adecuación de la regulación electoral a la realidad de la comunicación en nuestros días, con una pluralidad de medios que van más allá de los tradicionales (prensa escrita, radio y televisión) para evitar quedar obsoleta. Un buen ejemplo de ello son los formatos audiovisuales realizados por la prensa digital, de indudable impacto y difusión, pero que curiosamente siguen al margen de las exigencias legales que la LOREG establece para los medios televisivos, como tendremos ocasión de analizar a continuación.

\section{IV.2. Los debates electorales televisados}

Uno de los formatos televisivos de más interés informativo — tanto para los medios de comunicación como para la ciudadanía- es el de los debates electorales, que inauguraron con éxito Richard Nixon y John Kennedy en 1960 y que se han convertido en una práctica generalizada en buena parte de los países democráticos. En España, sin embargo, las leyes guardan un absoluto silencio en este aspecto, lo que ha hecho que la doctrina haya reclamado, desde una visión institucional del proceso electoral ${ }^{64}$, su regulación y celebración, por considerarlos un medio idóneo para que, del enfrentamiento entre los distintos candidatos y de la exposición del contenido de sus programas, el elector obtenga mejor la información necesaria para tomar su decisión. Del mismo modo, no han faltado iniciativas legislativas dirigidas a imponer la obligatoriedad de celebrar debates electorales televisados, que no han prosperado finalmente ${ }^{65}$. Frente al monólogo y la propaganda, frente a la «reducción progresiva en el discurso de los líderes y en los contenidos racionales o ideológicos del mismo» ${ }^{66}$, los debates «constituyen el instrumento por excelencia de una idea constitucionalmente correcta de campaña electoral» ${ }^{67}$, pues priman el diálogo y contraste de ideas. Son, por tanto, «un expediente mucho más eficaz para formar la opinión pública» ${ }^{68}$, que permite a los ciudadanos votar «con suficiente conocimiento de causa y de personas, habiendo visto a los candidatos en el ejercicio de la actividad esencial y definitoria de la democracia, el libre, abierto y pacífico debate de las ideas» ${ }^{69}$.

64 Solozábal Echavarría, J. J., op. cit.

65 Proposición de Ley de modificación de la LOREG en materia de campañas y debates públicos presentada por el Grupo Parlamentario Socialista el 27 de octubre de 2003 (BOCG, Congreso de los Diputados, Núm. 13-365-1, de 27 de octubre de 2003) y Enmienda núm. 23 presentada por el Grupo Parlamentario Unidos Podemos-En Comú Podem-En Marea a la Proposición de Ley de modificación de la LOREG para el supuesto de convocatoria automática de elecciones (BOCG, Congreso de los Diputados, Serie B, Núm. 12B48-3, de 27 de octubre de 2016).

66 Porras Nadales, A., Representación y democracia avanzada. Cuadernos y debates, núm. 50, Centro de Estudios Constitucionales, Madrid, 1994, p. 75.

67 Rallo Lombarte, A., 1998, op. cit., p. 65.

68 Arnaldo Alcubilla, E., op. cit., p. 176.

69 González Encinar, J.J., «Elecciones sin debates», El País, 2 de marzo de 2000. Disponible en: http:/elpais.com/diario/2000/03/02/opinion/951951606_850215.html. 
La ausencia de cobertura legal propiciaría que, al depender exclusivamente de la voluntad de los candidatos, durante los primeros quince años de democracia en España no se celebraran debates electorales. A pesar de algunos intentos ${ }^{70}$, la falta de acuerdo entre las formaciones políticas y unos criterios excesivamente rígidos por parte de la Junta Electoral ${ }^{71}$, dificultarían su celebración. El primer cara a cara entre los principales líderes políticos (Aznar-González) tendría lugar, por fin, en sendos debates electorales, con ocasión de las elecciones generales de 1993 y curiosamente con la irrupción de las cadenas de televisión privadas: el primero el 24 de mayo de 1993, en Antena 3, y el segundo, una semana más tarde, en Telecinco. Resulta, cuando menos, paradójico, que no hayan sido los medios de comunicación estatales los encargados de asumir y consolidar esta práctica, ya que, tratándose de un servicio público esencial son la sede más apropiada para informar a los ciudadanos de las distintas opciones políticas que se presentan a las elecciones y someterlas al debate y al contraste. No hay que olvidar que el Estado tiene el deber de velar por el correcto funcionamiento del sistema democrático, que pasa por garantizar el ejercicio del derecho al sufragio en condiciones de libertad e igualdad, y para ello los ciudadanos han de poder acceder a una información veraz, neutral, completa y que respete el pluralismo político ${ }^{72}$. De ahí que algunos autores insistan en la necesidad de que los debates electorales se realicen en los medios de comunicación de titularidad pública ${ }^{73}$.

La celebración de este primer debate entre los dos líderes con más posibilidades de gobernar tendría lugar gracias a una flexibilización de los criterios de la Junta Electoral, que, ante la ausencia de regulación legal, ha ido concretando su régimen jurídico, por ser la encargada de velar por el cumplimiento de los principios de neutralidad y pluralismo ${ }^{74}$. Las directrices de la Junta Electoral en materia de celebración de debates electorales podrían sintetizarse así: 1. No hay obligación ni prohibición de celebrar debates electorales en los medios de comunicación audiovisuales, pero de pretenderse su realización ésta debe ser comunicada a la Junta Electoral. 2. La obligación de respetar los principios de neutralidad informativa y proporcionalidad rige igualmente en la celebración de debates electorales, tanto para las televisiones públicas como para las privadas. 3. El medio de

70 Suárez rechazaría debatir con González y Carrillo en las elecciones de 1979; el PSOE pondría condiciones que dificultarían el acuerdo con el resto de candidatos en las elecciones de 1982 para un debate en TVE que la JEC había autorizado (Acuerdo de la JEC 55/1982, de 22 de octubre).

71 La JEC exigió en un principio que se ofreciera a todas las fuerzas parlamentarias la posibilidad de participar en el debate electoral, excluyendo por tanto la celebración de debates bilaterales (Acuerdos de la JEC de 146/1989, de 3 de octubre; 254/1989, de 27 de octubre y 22/1992, de 5 de marzo).

72 Véase el interesante estudio de derecho comparado de FERnández Vivas, Y., Igualdad y partidos políticos: análisis constitucional y comparado de la igualdad de oportunidades de los partidos políticos, Congreso de los Diputados, Madrid, 2007, en el que se pone de manifiesto la práctica coincidencia de los distintos ordenamientos jurídicos para garantizar la igualdad de oportunidades en este ámbito.

73 Arnaldo Alcubilla, E., op. cit., p. 178.

74 Acuerdos de la JEC de 40/1993, de 16 de abril y 115/1993, 2 de junio. 
comunicación goza de libertad para optar por el formato de debate que prefiera, con el acuerdo de los candidatos que intervengan: debates bilaterales (cara a cara), plurilaterales con todos los candidatos con representación, plurilaterales con los candidatos de las formaciones con más votos (debates a tres, a cuatro), etc. 4. Existe obligación por parte del medio de comunicación de compensar a los candidatos de las formaciones políticas con representación que hayan quedado excluidas de debates electorales en contra de su voluntad, ya sea con otros debates, entrevistas o información electoral suficiente.

Hay que entender que la LOREG ni prohíbe ni tampoco obliga a celebrar debates electorales pero, si la dirección del medio en cuestión, que es a quien corresponde decidir la programación — sin que la Administración electoral pueda sustituirla en esta función-, decide llevarlos a cabo tendrán que comunicarlo a la Junta Electoral competente con cinco días de antelación, con precisión de todos los extremos en que deban realizarse los mismos (fecha, hora, intervinientes, etc. ${ }^{75}$. No estamos ante un simple requisito formal, sino que es un medio para garantizar potenciales recursos y evitar perjuicios irreparables, por eso la JEC prohibió la celebración de un debate por incumplir este requisito ${ }^{76}$. Se trata con ello de asegurar el respeto a los principios de neutralidad informativa y proporcionalidad, que la JEC extiende tanto a las cadenas de televisión públicas como a las privadas, ya se trate de un debate organizado por ellas mismas, ya se limiten a difundir la señal emitida por otra ${ }^{77}$. No están, en cambio, sujetos a las obligaciones del artículo 66 LOREG y de la Instrucción de la JEC 4/2011, los medios de prensa escrita, como El País, que organizó un debate a cinco el 30 de noviembre de 2015, ofreciendo la señal a todas las televisiones y medios digitales que quisieran emitirlo, pero sí éstas últimas ${ }^{78}$.

Los medios de comunicación audiovisuales, en ejercicio de su libertad de información, pueden elegir el formato de debate que prefieran, contando, claro está, con el consentimiento de los candidatos intervinientes (la intervención en los debates es voluntaria, por ello no es correcto escenificar con un asiento vacío el debate para mostrar la no participación de un candidato, ya que pudiera ser interpretado como una crítica negativa $)^{79}$. Pero tampoco cabe que el partido imponga al medio de comunicación la intervención de una persona distinta cuando aquél ha optado por

75 Instrucción de la JEC de 13 de septiembre de 1999, apartado Sexto.

76 Acuerdo de la JEC de 23 de noviembre de 2010.

77 Acuerdo de la JEC de 2 de diciembre de 2015, para las cadenas privadas que emitieron la señal del cara a cara organizado por la Academia de las Ciencias y las Artes de Televisión.

78 Acuerdo de la JEC de 530/2015, de 2 de diciembre, frente a la solicitud de suspensión del citado debate por parte de la formación UPyD, excluida del mismo.

79 STS de 10 de octubre de 2000. Si bien la no aplicación del art. 66 LOREG a los medios de prensa digital provoca una desigual situación ante este mismo hecho, por lo que se ha alertado sobre la posibilidad de que la regulación vigente quede obsoleta con el progresivo aumento de este tipo de debates (FERNÁNDEZ de Casadevante, P. «El régimen jurídico de los debates electorales en España», Cuadernos Manuel Giménez Abad, 11, 2016, p. 211). 
un debate en el que participen quienes encabezan las listas de las distintas formaciones políticas concurrentes, porque de lo contrario se pondría en entredicho la libertad de información (art. 20.1 d) CE ${ }^{80}$. En todo caso, para garantizar el principio de pluralismo político, «deben tener particularmente en cuenta los resultados obtenidos por cada formación política en las últimas elecciones equivalentes» ${ }^{81}$. En el supuesto de debates bilaterales o debates en los que no intervengan todos los candidatos, tienen que compensar la ausencia del resto de formaciones parlamentarias dándoles ocasión de participar en otros debates, programas de entrevistas, o cubriendo ampliamente la información de sus actos políticos.

Esta es además la doctrina del Tribunal Supremo que considera que los principios de igualdad, pluralismo y neutralidad informativa quedan garantizados tanto mediante debates bilaterales entre líderes de los partidos con mayor representación parlamentaria como a través de debates plurilaterales. En efecto, el Tribunal Supremo hubo de pronunciarse por primera vez con ocasión del recurso planteado por Izquierda Unida contra el Acuerdo de la JEC de 21 de mayo de 1993 que autorizó la celebración de los citados debates bilaterales entre los candidatos Aznar y González durante la campaña de las elecciones de 1993. Según esta doctrina, no cabe impedir la celebración de debates electorales televisivos cuando exista acuerdo entre los partidos y los medios de comunicación y siempre que, respetando el principio de proporcionalidad, se conceda de la mejor forma posible a las demás fuerzas políticas similar oportunidad (o lo que es lo mismo, siempre que se haga una «oferta igual» al resto de partidos) sin que en ningún caso se pueda «imponer un determinado formato informativo, que puede invadir la libertad del medio de configurar técnicamente esos formatos ${ }^{82}$.

Así las cosas, aunque la celebración de debates en los que participen todas las formaciones políticas que se presentan a las elecciones parece la opción más justa, se ha terminado teniendo en cuenta que «la fórmula del enfrentamiento directo entre los dos candidatos de los dos partidos que tienen la posibilidad real de formar gobierno es insustituible para que los ciudadanos puedan formarse una opinión» ${ }^{83}$. Y es que, sin duda, para que interesen a la ciudadanía y a los medios de comunicación es preciso que los debates se desarrollen entre un limitado número de

80 Acuerdo de la JEC 750/2011, de 1 de diciembre. Sobre las dificultades de ponderar la libertad de información y los principios de igualdad, pluralismo y neutralidad en el supuesto de que uno de los candidatos no pueda acudir al debate y el medio no acepte su sustitución por el siguiente en la lista, véase GARCía Mahamut, R. y Rallo Lombarte, A, op. cit., p. 236).

81 Instrucción de la JEC 4/2011, apartado Octavo.

82 STS de 13 de febrero de 1996.

83 Pérez Royo, J., «Debates electorales», El País, Andalucía, 3 de marzo de 2000. Disponible en: http://elpais.com/diario/2000/03/03/andalucia/952039325_850215.html Reviriego se muestra, en cambio, más escéptico, teniendo en cuenta los intereses y conveniencias de los medios de comunicación que los promueven y el riesgo de manipulación de la información que finalmente llega a la ciudadanía a través de este formato (Reviriego Picón, F., «Yolanda Fernández Vivas: Igualdad y partidos políticos. Análisis constitucional y comparado de la igualdad de oportunidades de los partidos políticos; Óscar Sánchez Muñoz: La igualdad de oportunidades en las competiciones electorales», Teoría y Realidad Constitucional, 23, 2009, p. 576). 
representantes de las formaciones políticas, entre aquellos que mayores posibilidades tienen de acceder al gobierno ${ }^{84}$. En efecto, el formato de debate «cara a cara» volvió a reproducirse quince años después del primero ${ }^{85}$, enfrentando esta vez a los candidatos Rajoy y Zapatero, durante la campaña de las elecciones de 2008, en la Academia de las Ciencias y Artes de Televisión, que originó una señal institucional retransmitida por numerosas cadenas. Nuevamente, con ocasión de las elecciones de 2011, la Academia celebraría otro debate entre los candidatos Rajoy y Rubalcaba. No obstante, con el surgimiento de nuevas formaciones políticas que han alcanzado una importante presencia en nuestro sistema de partidos, en las campañas de las pasadas elecciones de 2015 y 2016, han cobrado protagonismo e interés informativo formatos plurilaterales reducidos como el «debate a cuatro» con la participación de Podemos y Ciudadanos junto al PP y PSOE, debates «cara a cara», no solo entre los líderes de las dos formaciones mayoritarias (Rajoy y Sánchez) sino también entre los cabezas de lista de los partidos emergentes (Iglesias y Rivera), o incluso «debates a cuatro» entre candidatas, organizados tanto por la Academia de Televisión como por cadenas privadas. Parece, por tanto, que tras treinta años de democracia sin debates electorales, se ha consolidado la idea de que los debates constituyen un elemento necesario de la campaña electoral y la resistencia a participar en ellos es valorada negativamente por la opinión pública.

Sea cual sea el formato de debate escogido — «no es competencia de la JEC imponer a una televisión privada quiénes deben participar en los debates que éstas decidan libremente organizar o difundir ${ }^{86}$ - , la JEC obliga al medio a compensar a las formaciones políticas parlamentarias ausentes, en una fórmula que trata de garantizar el equilibrio entre la libertad del medio de comunicación y la garantía del pluralismo ${ }^{87}$. Así, el medio puede tener en cuenta el hecho de tener grupo parlamentario propio como criterio objetivo para decidir qué candidatos se enfrentan en el debate, siempre que compense de algún modo al resto de los pertenecientes al grupo mixto ${ }^{88}$. Puede igualmente incluir en un debate con otros candidatos a los representantes de los «grupos políticos significativos» - que a pesar de no tener representación parlamentaria obtuvieron el $5 \%$ de los votos en elecciones recientes no equivalentes (Ciudadanos y Podemos) ${ }^{89}$ - , siempre que se compense a los líderes de las formaciones que obtuvieron representación en las últimas elecciones equivalentes ${ }^{90}$.

84 Santolaya Machetti, P., op. cit., p. 276.

85 Tras tres elecciones generales sin debates electorales (1996, 2000 y 2004).

86 Acuerdo de la JEC de 516/2015, de 2 de diciembre.

87 Delgado-Iribarren García-Campero, M., "Artículo 66», en Delgado-Iribarren GarCía-Campero, M., (coord.), Comentarios a la Ley Orgánica del Régimen Electoral General y a la Ley Orgánica del Referéndum, La Ley, Madrid, 2014, p. 773.

88 Acuerdo de la JEC 678/2011, de 3 de noviembre.

89 Ciudadanos obtuvo el 5,85\% las elecciones locales (2015) y Podemos el 7,98\% en las europeas (2014).

90 Acuerdo de la JEC 516/2015, de 2 de diciembre. 
La Junta Electoral no impone una forma concreta de compensar, sino que respeta la libertad de información del medio de comunicación, pero se permite controlar si son medidas compensatorias suficientes. Por eso, la comunicación de cuáles sean las medidas compensatorias no puede ser genérica («seguimiento informativo relevante a través de programas emitidos por la cadena») sino que éstas han de concretarse en la participación en debates bilaterales o plurilaterales, entrevistas o programas de información, señalando la forma y el momento en que va a realizarse dicha compensación, con indicación de la fecha y hora de emisión ${ }^{91}$. La JEC ha considerado suficiente compensación por estar ausente en un debate a cuatro la participación en otro debate electoral a siete ${ }^{92}$, o la participación en dos entrevistas en dos cadenas del mismo medio ${ }^{93}$. Ahora bien, siguiendo el criterio del Tribunal Supremo ${ }^{94}$, exige que la compensación no se aparte sustancialmente de las condiciones de realización y emisión observadas en el debate en el que las formaciones fueron excluidas, ya que de no ser así los principios de igualdad, pluralismo y neutralidad se verían conculcados. Por esta razón, ha llegado a exigir que la medida compensatoria se emita en una franja horaria determinada ${ }^{95}$.

Con independencia de que la celebración de estos debates influya o no de manera determinante en el sentido del voto de los ciudadanos ${ }^{96}$, lo que sí parece comprobado es que, al menos, con este tipo de programas los medios de comunicación logran movilizar al electorado, fomentando la participación en las elecciones, algo, sin duda, saludable en todo sistema democrático y que es un objetivo en el que deben poner su empeño los poderes públicos, como ordena la Constitución (artículo 9.2).

Como ha señalado el Tribunal Constitucional, «la importancia que el derecho de sufragio tiene en el sistema democrático justifica que los poderes públicos traten de favorecer la participación» ${ }^{97}$ y no es una medida deseable sino que además «constituye mandato constitucional de los poderes públicos facilitar la participación de los ciudadanos en la vida política, social y cultural» ${ }^{98}$, lo que deben

91 Acuerdo de la JEC 507/2015, de 2 de diciembre, en respuesta a una reclamación de UPyD contra Atresmedia por quedar excluida de un debate a cuatro en La Sexta. En el mismo sentido, Acuerdo de la JEC 151/2016, de 15 de junio, por la exclusión del debate a cuatro entre mujeres en Antena 3.

92 Acuerdo de la JEC de 582/2015, de 15 de diciembre. En el mismo sentido, el Acuerdo de la JEC de 8 de junio de 2016, tiene en cuenta la diferencia entre el 13,94\% de votos y los 40 escaños de Ciudadanos frente al 2,25\% de votos y 8 escaños de CDC para justificar la diferencia de trato y considerar suficiente la fórmula del debate a siete para compensar la ausencia en el debate a cuatro de CDC.

93 Acuerdo de la JEC 583/2015, de 15 de diciembre.

94 STS de 16 de noviembre de 2009, obligando a emitir un debate plurilateral compensatorio de un debate a dos, a la misma hora que éste y no a otra de menos audiencia.

95 Acuerdo de la JEC de 9 de diciembre de 2015, para que el debate a ocho en La 1 de TVE se emitiera a una hora de verdadera máxima audiencia como el debate a dos, pasando de las $24.00 \mathrm{~h}$ a las $22.00 \mathrm{~h}$.

96 Véase el estudio de Luengo, O. C., «Debates electorales en televisión: una aproximación preliminar a sus efectos inmediatos», Revista Española de Ciencia Política, 2011, 24, pp. 81-96.

97 STC 189/1993, de 14 de junio, FJ. $5^{\circ}$ y ATC 346/1991, de 15 de noviembre.

98 STC 208/1989, de 14 de diciembre, FJ. $3^{\circ}$ y ATC 346/1991, de 15 de noviembre. 
hacer garantizando que el ejercicio de este derecho se sustente en la optimización de los medios informativos/formativos de la opinión pública electoral ${ }^{99}$.

Dicho esto, hay que reconocer que, en la práctica, más allá de estos criterios que persiguen garantizar el pluralismo, los partidos políticos imponen sus propias reglas: negociando las condiciones de celebración de los debates hasta el más mínimo detalle; exigiendo que los tiempos de intervención se cronometren; pactando los temas a debatir; el orden de intervención de los candidatos; el papel del periodista que va a moderarlo, a quien muchas veces se impide hacer preguntas; etc.

Como resultado del celo excesivo por parte de los partidos políticos a la hora de controlar el formato y reducir el riesgo de exposición del candidato o candidata, los debates pueden llegar a perder buena parte del interés informativo. Y terminar siendo unos debates tan encorsetados que, muchas veces no son sino reiteración del mismo mensaje que se reproduce en otros espacios publicitarios. El diálogo vuelve a ser sustituido por la yuxtaposición de monólogos de los representantes políticos y la excesiva rigidez se ve acentuada por la falta de intervención de los profesionales de los medios de comunicación. Por todo ello, sería deseable un mayor equilibrio entre la exigencia de igualdad y pluralismo político, de un lado, y la libertad de información, de otro. O lo que es lo mismo, que las limitaciones a las que tienen que someterse los profesionales de la información para garantizar la igualdad de oportunidades no vacíen de contenido la libertad de información. En esta línea parece avanzarse aunque sea tímidamente en los debates celebrados con ocasión de las dos últimas elecciones generales de 2015 y 2016, sin bloques temáticos y con flexibilidad en los tiempos.

\section{IV.3. La publicación de sondeos electorales: ¿una prohibición desfasada?}

Dentro de la labor informativa de los medios destaca la de indagar acerca de la intención de voto de la ciudadanía y su evolución durante la campaña electoral y publicar los resultados de estos sondeos o encuestas electorales. El Estado ha entrado también a regular este aspecto como uno de los elementos singulares de la campaña electoral. De un lado, y de manera razonable y lógica, establece requisitos que pretenden asegurar el rigor en la realización de los sondeos, para garantizar de este modo el derecho a recibir una información veraz (art. 20.1.d CE). De otro, y de forma un tanto anacrónica y poco justificada, prohibiendo su publicación y difusión en los cinco días anteriores a las elecciones.

La Ley Electoral exige rigor en la publicación de encuestas y sondeos electorales, obligando a los medios de comunicación a dar detallada información sobre las características técnicas del mismo: sistema de muestreo, tamaño de la

99 Rallo Lombarte, A., 1998, op. cit., p. 81. 
muestra, margen de error, nivel de representatividad, procedimientos a través de los que se han seleccionado a los encuestados y fecha de realización del trabajo de campo ${ }^{100}$. Además, de hacer públicos igualmente el nombre de la entidad realizadora del sondeo, el de la persona que ha encargado su realización, el texto íntegro de las cuestiones planteadas y el número de personas que no han contestado a cada una de ellas (art. 69.1 LOREG).

Con tales exigencias se pretende evitar hacer llegar a los electores, en tan crucial período, informaciones manipuladas deliberadamente o falseadas que puedan influir en el ejercicio del derecho fundamental al voto, siendo la JEC el órgano encargado de velar por el cumplimiento de tales exigencias y el que puede exigir a los medios de comunicación, en su caso, la publicación de las rectificaciones necesarias $^{101}$.

La prohibición de publicar sondeos electorales cinco días antes de las elecciones ha sido cuestionada por la doctrina que ha llegado a tacharla de inconstitucional $^{102}$, por considerar que vulnera el derecho fundamental a recibir información en un momento en que debería contar con la máxima protección dada la trascendencia que éste tiene para el ejercicio en condiciones de libertad del derecho a participar en los asuntos públicos. Lejos de rectificar, el legislador trató de reforzar esta medida, en la reforma de la LOREG realizada en 2011, prohibiendo no solo la «publicación», sino también la «difusión o reproducción» de los sondeos y encuestas en este período por cualquier medio de comunicación ${ }^{103}$. Asimismo, la JEC es estricta con el cumplimiento de la prohibición recordando incluso, cuando es consultada, las sanciones previstas en la LOREG; de este modo, en relación con un sondeo acerca de la valoración de un debate electoral por parte de los telespectadores, ha llegado a prohibir que se publiquen resultados a determinadas preguntas cuya respuesta directa o indirectamente pudiese traslucir la intención de voto de los electores ${ }^{104}$.

Se supone que con tal prohibición se pretende conseguir un doble objetivo: de un lado, proteger la libertad del derecho al voto, reduciendo la influencia que puedan tener las encuestas en los días de reflexión y, de otro, hacer posible su rectificación a tiempo antes del día de las votaciones en el caso de incumplimiento de la normativa que vela por su objetividad. En relación con el primero de los objetivos, cabría cuestionar la idea de que la libertad con que debe ejercerse el derecho al voto vaya a verse realmente afectada con el conocimiento de la intención de voto declarada por los electores en tales sondeos los días previos a la

100 Véase Gálvez Muñoz, L. A., Régimen jurídico de la publicación de las encuestas electorales, Congreso de los Diputados, Madrid, 2002.

101 Arts. 69.2 y 69.4 LOREG.

102 GÁlvez Muñoz, L. A., Régimen jurídico de la publicación de las encuestas electorales, Congreso de los Diputados, Madrid, 2002.

103 Art. 69.7 LOREG en la redacción dada por la LO 2/2011, de 28 de enero.

104 Acuerdo de la JEC 577/2015, de 14 de diciembre. 
jornada electoral. No hay duda de que los sondeos electorales pueden incidir en cierto modo en la ciudadanía, quizás no tanto en la decisión de optar por un partido u otro, sino sobre el hecho mismo de votar. En efecto, en función de si los resultados del sondeo presentan a un partido como claro ganador o, por el contrario, muestran una reñida competición, las encuestas pueden influir a la hora de movilizar al electorado o hacer que éste pierda el interés en acudir a las urnas. No obstante, no dejan de ofrecer un elemento importante que completa la información de los ciudadanos a la hora de votar, constituyen un elemento más de juicio que no tiene por qué coartar su libertad ni impedir un ejercicio racional del derecho al voto ${ }^{105}$.

En relación con el segundo de ellos, el de asegurar la efectividad de las normas que garantizan la objetividad de las encuestas, dando margen temporal a la Junta Electoral para ejercer el control sobre los sondeos publicados y obligar a los medios a realizar las rectificaciones oportunas, habría que señalar que el riesgo de que un sondeo irregular no se rectifique a tiempo sigue existiendo a pesar la de la prohibición, dado lo breve de los plazos. En todo caso, tampoco habría que sobredimensionar el impacto de una encuesta o sondeo irregular sobre la ciudadanía, sobre todo existiendo la posibilidad de contrarrestarlos con otros que pudieran publicarse libremente sin esa prohibición. Los electores, en su mayoría, son conscientes de que las encuestas solo reflejan una aproximación de la intención de voto de los ciudadanos y cuentan con madurez para valorar la credibilidad que les merece una u otra. Así, en algunos países de nuestro entorno, como Francia, se ha reconsiderado esta prohibición restringiéndola únicamente a la jornada de reflexión, cayendo, por tanto, el argumento de la rectificación frente a la garantía de la libertad de información ${ }^{106}$.

Sea como fuere, lo que sí ha demostrado la experiencia, especialmente de las dos últimas elecciones generales es que se trata de una prohibición alejada de la realidad sobre la que pretende actuar y, por tanto, ineficaz. La ciudadanía, gracias a Internet, tiene hoy día un fácil acceso a medios de comunicación extranjeros que realizan sondeos y encuestas sobre intención de voto en nuestro país. Por más que la JEC establezca que los medios digitales han de respetar las mismas restricciones recogidas en la LOREG que los medios de comunicación tradicionales ${ }^{107}$, la prohibición resulta inoperante dada la dificultad de perseguir su incumplimiento, sobre todo cuando la difusión la llevan a cabo centenares o miles de

105 Un 59,2\% de los españoles con derecho a voto reconocen haber tenido conocimiento de los resultados de algún sondeo electoral en las pasadas elecciones generales del 2016, aunque el $81.7 \%$ no los tuvo nada en cuenta para decidir su voto. Del 19,3\% que tuvo en cuenta esta información al 31,7\% le animó a votar y al 35,5\% a reforzar su decisión sobre el partido político al que pensaba votar. Barómetro Postelectoral del CIS, julio 2016, Estudio 3145, disponible en http://www.cis.es/cis/export/sites/default/-Archivos/Marginales/3140_3159/3145/es3145mar.pdf

106 La Ley 214/2002, de 19 de febrero, de reforma de la Ley de 19 de julio de 1977.

107 Instrucción de la JEC 4/2007, de 12 de abril, sobre la utilización de las nuevas tecnologías de la información y de la comunicación electrónicas como instrumento de propaganda electoral. 
ciudadanos a través de redes sociales, blogs, mensajería instantánea, etc ${ }^{108}$. Un ejemplo de la facilidad con la que puede burlarse la prohibición es la proyección pública adquirida por cuentas y proyectos dedicados en exclusividad a seguir los sondeos electorales, como el caso Electograph (@Electograph), difundiendo de manera enmascarada los resultados de la encuesta de El Periòdic d'Andorra, con el símil del mercado de la fruta y verdura del país vecino ${ }^{109}$.

Por todo ello quizás lo más razonable y adecuado a la realidad de nuestros días sería suprimir una prohibición que se ha vuelto anacrónica e inoperante, y que pone en entredicho el derecho de los ciudadanos a recibir información para poder ejercer en condiciones de libertad su derecho a participar en los asuntos públicos ${ }^{110}$.

\section{REFLEXIONES FINALES}

Los más recientes procesos electorales, y en especial las elecciones generales de 2015 y 2016, han puesto de manifiesto que nos encontramos ante un nuevo escenario en el que destacan, de un lado, la irrupción de nuevas formaciones políticas que han cuestionado el bipartidismo hasta entonces imperante y, de otro, la generalización de tecnologías de la información y comunicación, que se han sumado con fuerza a las ya tradicionales (prensa, radio y televisión) para informar a la ciudadanía en el ejercicio de su derecho al sufragio. En este contexto, la mediatización de la vida política ha seguido siendo una constante y resulta innegable que el surgimiento y consolidación electoral de los nuevos partidos políticos (Podemos, Ciudadanos) habría sido impensable sin la intervención de los medios de comunicación.

Los medios de comunicación, en especial las cadenas de televisión y la prensa digital, han recuperado el protagonismo de formatos más atractivos para la ciudadanía, como entrevistas y debates, no solo bilaterales (cara a cara) sino también plurilaterales (debates a cuatro) en los que se enfrenten los programas y líderes de las principales formaciones concurrentes, con un concepto de campaña electoral más cercano a la idea de la información que a la de la propaganda. Ha de destacarse, además, la incorporación en estos espacios de los «grupos políticos significativos» (Instrucción de la JEC 1/2015).

Sin embargo, en otros muchos aspectos la LOREG no parece haberse adaptado a esta nueva realidad, manteniendo una regulación muy centrada en la publicidad electoral (prohibición en los medios públicos y televisión privada, limitación del gasto en publicidad en la prensa escrita y radio privada, cesión de espacios gratuitos

108 Sobre la obsolescencia de la prohibición véase también REviriego Picón, F., 2009, op. cit., p. 578 .

109 http://www.electograph.com/search/label/Generales

110 El Consejo de Estado también se ha mostrado partidario de su supresión. Informe del Consejo de Estado sobre las propuestas de modificación del régimen electoral general, de 24 de febrero de 2009. 
en los medios públicos), ignorando que los ciudadanos muestran mayor interés por los espacios de contenido informativo y especialmente, por aquellos en los que se confrontan las formaciones políticas. Asimismo la ley permanece callada ante el papel que juegan las tecnologías de la información y comunicación en el proceso electoral, cuando debería al menos tener en cuenta la incidencia de la prensa digital (como muestra, la celebración de debates digitales que pueden alcanzar idéntica o mayor difusión que los realizados por las cadenas de televisión). La ineficacia y obsolescencia de algunas de las medidas aún recogidas en la LOREG, como la prohibición de difundir encuestas electorales durante los cinco días anteriores a las elecciones, también se han puesto en evidencia durante la campaña electoral.

El legislador continúa sin regular los debates (su celebración sigue dependiendo en última instancia de la voluntad de los candidatos y de los medios de comunicación) y se limita a establecer los principios que deben presidir el tratamiento de la información electoral en el artículo 66 LOREG, que ha sido desarrollado por la Instrucción de la JEC 4/2011. En cumplimiento de esta regulación, se han trasladado los criterios del reparto de espacios publicitarios de los partidos políticos a los programas informativos, aplicando, «cronómetro en mano», una proporcionalidad aritmética en base a los resultados de las últimas elecciones equivalentes. De este modo, la información que se emite, hoy por hoy, sobre la campaña electoral, tanto en los medios de comunicación públicos, como en las cadenas de televisión privadas, es una información encorsetada en bloques cronometrados, cuyo orden de aparición ni siquiera viene marcado por criterios periodísticos. Por el contrario, la práctica más reciente ha mostrado una mayor flexibilización de los debates, fomentada por los criterios de la Junta Electoral.

Reconociendo la dificultad de alcanzar el justo equilibrio entre la exigencia de igualdad y respeto al pluralismo político que los medios han de guardar, de un lado, y el ejercicio de la libertad de información, de otro, no cabe duda de que habría que avanzar hacia su consecución sin vaciar a esta última de contenido. Sería aconsejable dejar de exigir a las cadenas de televisión privadas los mismos principios de neutralidad y proporcionalidad que se imponen a los medios de comunicación públicos, y que cuestionan su libertad de información. Porque una cosa es que se controle el adecuado reflejo en el medio televisivo de la pluralidad de opciones políticas entre las que la ciudadanía ha de elegir con su voto y otra muy distinta que los espacios de información electoral se conviertan, como viene siendo la tónica, en una reiteración de los espacios de propaganda. Asimismo sería conveniente permitir que el pluralismo político se manifieste en la pluralidad de medios de comunicación existentes, y otorgar un mayor grado de confianza a la madurez del electorado, capaz de discernir las distintas líneas editoriales de los medios de comunicación, y a los periodistas que han de ser y son los primeros interesados en ejercer su labor periodística con el rigor que el electorado merece y que exige el derecho a la información como sustento de la democracia. 
TITLE: Publicity and information about elections in the media during the electoral campaign.

AвSTRACT: General elections of 2015 and 2016 showed a context, with new parties that extend political pluralism and new ways of communication and information, that invites to rethink the regulation of some aspects of the electoral campaign by the LOREG: namelly those relating to advertising and electoral information. An analysis that has to put the emphasis on ensuring equal opportunities for all the parties that concurre to the elections, by respecting neutrality and political pluralism in the electoral information, but without emptying the freedoms of expression and information constitutionally guaranteed.

RESUMEN: Las elecciones generales de 2015 y 2016 nos han mostrado un escenario, con nuevos partidos que amplían el pluralismo político y nuevas formas de comunicación e información, que invita a realizar un replanteamiento de la regulación de algunos aspectos de la campaña electoral por la LOREG: concretamente los referidos a la publicidad y a la información electoral. Un análisis que ba poner el acento en la garantía de la igualdad de oportunidades de todas las formaciones que concurren a las elecciones, tratando de asegurar la neutralidad y el respeto al pluralismo político en la información electoral, pero sin vaciar de contenido las libertades de expresión e información constitucionalmente garantizadas.

KEY WORDS: political parties/medial electoral campaign/ electorate/ elections/ electoral publicity/electoral TV debates/ free electoral advertising/ freedom of the press/ neutrality

Palabras Clave: partidos políticos/medios de comunicación/ campaña electorall elecciones/publicidad electoral/ debates electorales televisados/ espacios electorales gratuitos/ libertad de información/ neutralidad

FECHA DE RECEPCIÓN: 12.06.2017

FECHA DE ACEPTACIÓN: 26.07.2017 
